\title{
A Retrospective Study of the Prevalence of Female Infertility in the Southwest Region, Cameroon
}

\author{
Akah Roland Tiagha ${ }^{*}$, Moses Ngemenya ${ }^{1}$, Jude Eteneneng Enoh ${ }^{1,2}$, Jules Clement Assob Nguediaa,3 \\ ${ }^{1}$ Department of Medical Laboratory Sciences, Faculty of Health Sciences, University of Buea, Buea, Cameroon \\ ${ }^{2}$ Medical Research Centre, Institute of Medical Research and Medicinal Plant Studies, Yaounde, Cameroon \\ ${ }^{3}$ Faculty of Medicine and Pharmaceutical Sciences (FMSP), University of Douala, Douala, Cameroon \\ Email: ^akahrawlings@yahoo.com
}

How to cite this paper: Tiagha, A.R., Ngemenya, M., Enoh, J.E. and Nguedia, J.C.A. (2020) A Retrospective Study of the Prevalence of Female Infertility in the Southwest Region, Cameroon. Open Journal of Obstetrics and Gynecology, 10, 1728-1740.

https://doi.org/10.4236/ojog.2020.10120156

Received: October 8, 2020

Accepted: December 22, 2020

Published: December 25, 2020

Copyright $\odot 2020$ by author(s) and Scientific Research Publishing Inc. This work is licensed under the Creative Commons Attribution International License (CC BY 4.0).

http://creativecommons.org/licenses/by/4.0/

\begin{abstract}
Background: Infertility is a major reproductive health care problem that affects the wellbeing of women. Although views vary between cultures, infertility is seen almost exclusively as a woman's problem in Africa with secondary infertility being the most prevalent while sexually transmitted infections the most investigated cause of infertility. Objective: The aim of this study was to determine the prevalence of female infertility in the Limbe and Buea Regional hospitals of the Southwest region of Cameroon from 2015-2019. Materials and Methods: A retrospective descriptive design was used which involved studying clinical files of women within the reproductive age group (15 - 49) with infertility problems, at the gynaecological and maternity units of the selected hospitals in the Southwest region of Cameroon over a period of five years (2015-2019). Data were collected from all files included in the study. Results: A total of 4609 females visited the two hospitals for investigation and 1111 files were identified with infertility giving prevalence of $24 \%$. Three hundred and forty-three $(343 ; 31 \%)$ presented with primary infertility while seven hundred and sixty-eight $(768 ; 69 \%)$ had secondary infertility. The average age of affected female was 31.5 making age the predisposing factor of infertility because after the peak of 25 years, infertility started decreasing. Employment with salary and the association between diagnosis and age had a p-value $<0.005$ which was considered significant in this study. Conclusion: This study found that the prevalence of infertility in Southwest Cameroon is high with secondary infertility being most predominant among infertile women with a prevalence of $69 \%$ caused principally by sexually transmitted infection (STIs). Age and occupation were significantly associated with infertility. Routine laboratory screening of women of reproductive age may reduce the high prevalence of infertility in the study area.
\end{abstract}




\section{Keywords}

Female Infertility, Laboratory Investigations, SW Region Cameroon

\section{Introduction}

Infertility is a vital issue for couples of childbearing age worldwide. It is a special reproductive health defect that is not life threatening, but has considerable, detrimental influence on couples, their families and the society [1] [2]. The World Health Organization (WHO) has identified infertility as a global public health problem [2] [3]. According to Cooper and collaborators, infertility is the inability of a couple to achieve conception over a period of one year (in a woman under 35 years of age) or 6 months (in a woman above 35 years of age) despite adequate, regular (3 - 4 times per week) and unprotected sexual intercourse. Furthermore, the American Society for Reproductive Medicine (ASRM) which defines infertility similarly advises commencement of evaluation and treatment based on clinical history and physical examinations in women over 35 years after 6 months [4]. With the various definitions of infertility, the acceptable definition most definitely depends on the couple involved, the nature of the problem identified, the socio economic and cultural dynamics of the community in question and the relative time expected to conceive by an average couple. Considering these factors, the World Health Organization (WHO) proposed a more universal definition for infertility as "a disease of the reproductive system defined by the failure to achieve a clinical pregnancy after 12 months or more of regular unprotected sexual intercourse" [4] [5]. Meanwhile the WHO's epidemiologic definition of infertility is "women of reproductive age at risk of becoming pregnant who report unsuccessfully trying for a pregnancy for more than two years" since some may not conceive within one year of unprotected sex [5].

Infertility is divided into two groups; primary when a couple has not previously initiated a pregnancy and secondary when they have been successful with at least one previous pregnancy. It is reported to range from $0.6 \%$ to $3.4 \%$ for the primary infertility and $8.7 \%$ to $32.6 \%$ for secondary infertility over the past ten years [6] [7] [8].

Despite cultural differences, infertility is seen almost exclusively as a woman's problem in Africa and Asia. Furthermore, there appears to be gender bias in research on management of infertility as many studies have focused on the women, reinforcing the belief that infertility is mainly caused by female factors [9]. In Kenya, infertility is assumed to be a female disorder and husbands rarely accompany wives to infertility clinics [9] [10]. Anecdotal evidence indicates some parts of Cameroon strongly believe in pronatalism hence highly stigmatize childlessness [11].

Prevalence of infertility is the percentage of women of reproductive age (15 to 49 years) at risk of pregnancy who report trying unsuccessfully for a pregnancy 
for one year or more" [12] [13]. About 60 - 80 million couples are affected by infertility worldwide and the figure is increasing [9] [14]. Infertility can be due to the woman, man, both or idiopathic [15] [16]. The prevalence of primary infertility in developed and developing countries is $6.6 \%-26.4 \%$ and $5 \%-25.7 \%$ respectively [17]. Cong and collaborators also reported the prevalence of primary infertility in China to be $9 \%$, America to be $10 \%-15 \%$, Siberia to be $16 \%$ and Iran to be $78.4 \%$ [1] [16] [17]. Overall, global infertility is estimated at $10 \%$ $15 \%$ [18]. In Nigeria and parts of Sub-Saharan Africa (SSA) including Cameroon, infertility rate could exceed 30\% [19] [20] hence constitutes a major public health problem. However, secondary infertility is more prevalent compared to the global picture with 52\% in Sub-Saharan Africa, $40 \%$ in Latin America and in contrast, only $23 \%$ in Asia and $16 \%$ in North Africa [10] [20] [21]. Secondary infertility may be caused by genital infections with sexually transmitted infections (STIs) responsible for more than half of the cases [21].

The prevalence of primary infertility is calculated as the number of women in an infertile union divided by the number of women in both infertile and fertile unions, where women in a fertile union have had at least one live birth and have been in the union for at least five years at the time of the survey. Prevalence of secondary infertility is calculated same but women in a fertile union have successfully had at least one live birth in the past five years and, at the time of the survey, [10]. In Sub-Saharan Africa region, the prevalence was lowest in East Africa and Southern Africa. In contrast, some countries, mostly in central Sub-Saharan Africa, had very high prevalence: [12] [22].

Though infertility is high in South East Asia and Sub-Saharan Africa it has received little research and policy attention. Whereas there is much data on infertility in high-income countries as well as in other African countries [1]-[6] [8] [9] [10] [11], there is paucity of information on endocrine disorders related to infertility in Cameroon [21]. There are no reports on nationwide survey of infertility undertaken in Cameroon and the Southwest region in particular but it is assumed that the rate is similar to that in neighboring countries. This study therefore investigated the prevalence of infertility and the causes in the Southwest region of Cameroon, in order to generate data which may be exploited in addressing this problem of high public health concern.

\section{Materials and Methods}

Study area: The research was conducted at the gynaecological and maternity units of the Limbe and Buea Regional Hospitals in the Fako Division in the Southwest region of Cameroon. These two hospitals were chosen because they are the most referenced gynaecological centers in the Southwest region of Cameroon.

Study design and study population: A retrospective descriptive design was used. This involved studying of clinical files of women within the reproductive age group (15 - 49) with infertility problems, at the gynaecological and maternity unit of the selected hospitals in the Southwest region of Cameroon over a period of five years (2015-2019). Data were collected from all the documented files of 
clinical and laboratory findings.

Inclusion criteria: Clinical files from the hospital register of women of reproductive age group (15 - 49 years) with infertility problems from 2015-2019.

Exclusion criteria: Missing or incomplete clinical files of women of reproductive age group (15 - 49 years) with infertility problems from 2015-2019.

Ethical consideration and Administrative Authorizations: This study was approved by the Institutional Review Board of the Faculty of Health Sciences of the University of Buea with Ref: 2019/1007-08/UB/SG/IRB/FHS. Administrative authorization was obtained from the Regional Delegation of Public Health, Southwest region with ref: R11/MINSANTE/SWR/RDPH/PS/195/678 and the hospitals. A structured questionnaire of patient's data was used in conformity with the Helsinki declaration.

Data collection: It was done using a structured questionnaire based on documented files and laboratory findings. Variables addressed were age of the patient, occupation, diagnosis, resident of the patients, laboratory investigation and body mass index.

Data analysis: Data were sorted, cleaned and coded. The data were entered into a database and analyzed using Epi Info 7. Data were presented in tables, frequencies and percentages of the variables and Chi square $\left(\mathrm{X}^{2}\right)$ with $\mathrm{p}$-value of $<0.05$ considered statistically significant.

\section{Results}

From a total number of 4609 females who visited the gynaecological and maternity units of the Limbe and Buea Regional Hospitals from 2015-2019, 1111 patients' files were identified with infertility giving a prevalence of $24 \%$. Prevalence is the percentage of women of reproductive age (15 - 49 years) at risk of becoming pregnant (not pregnant, sexually active, not using contraception and not lactating) who report trying for a pregnancy for two years.

Of the 1111 identified files; 343 were suffering from primary infertility while 768 had secondary infertility, corresponding to prevalence values $7.4 \%$ and 17.6\% as shown in Figure 1.

\section{Association between age and infertility}

With respect to age, women below 35 years were 971 (79\%) and those above 35 years were 240 (22\%) shown in Figure 2(a) indicating that infertility cases are detected more below 35 years of age and less above 35 years. Figure 2(b) shows the specific decrease of infertility from menarche to the peak of 35 years and declines as age increases.

There exist an association between age group and diagnosis $\left(\mathrm{X}^{2}=13.6668\right.$; $\mathrm{p}$-value $=0.0002182748$; at $\mathrm{CI}=95 \%)$ as shown in Table 1 indicating that age is a predisposing factor of infertility.

\section{Association between occupation and infertility}

It was observed that jobs with salary had the greatest number of infertility cases followed by women doing business and the least is noticed in farmers (Figure 3 and Table 2). 


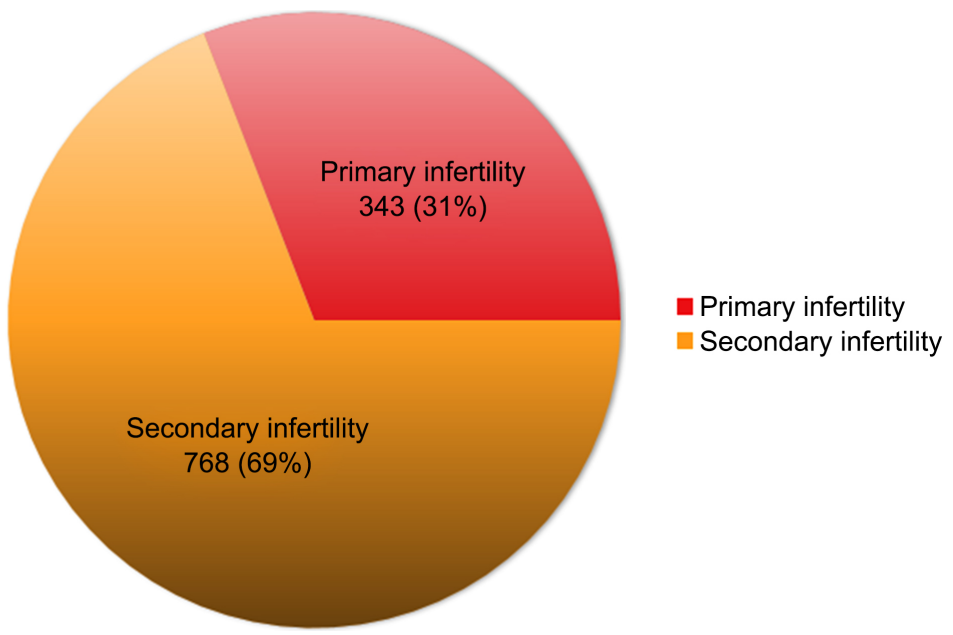

Figure 1. Frequency of primary and secondary infertility.

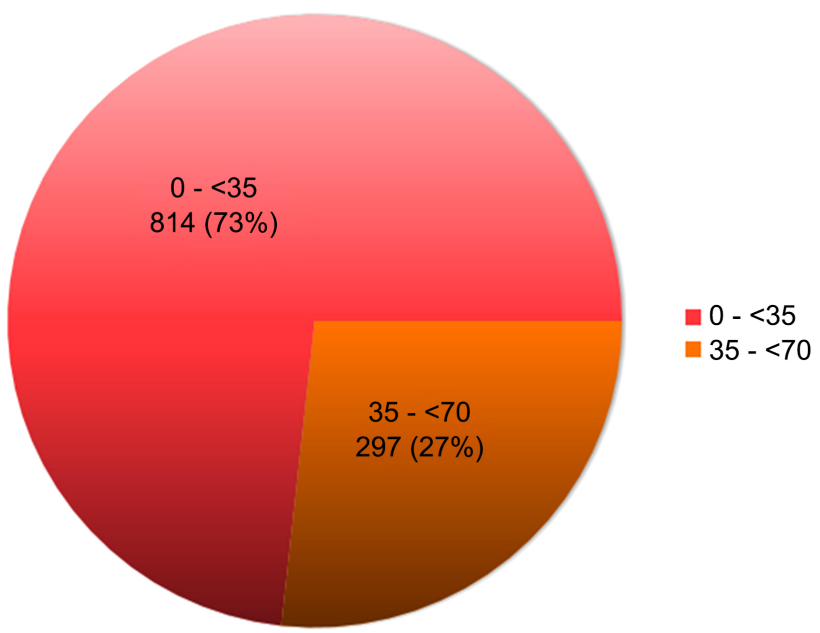

(a)

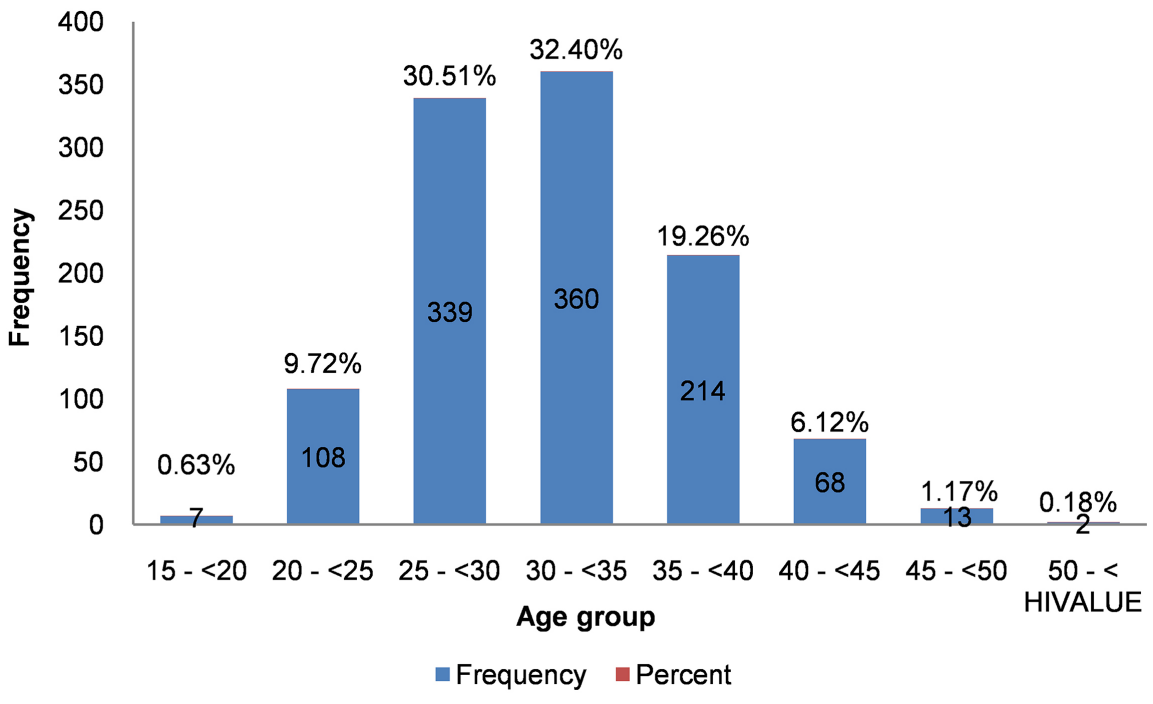

(b)

Figure 2. (a) Frequency of infertility below and above 35 years; (b) The frequency of infertility in specific age group. 
Table 1. Relationships between age group and diagnosis.

\begin{tabular}{cccccc}
\hline \multirow{2}{*}{ Age group } & \multicolumn{2}{c}{ Diagnosis } & & & \\
\cline { 2 - 3 } & $\begin{array}{c}\text { Primary } \\
\text { infertility }\end{array}$ & $\begin{array}{c}\text { Secondary } \\
\text { infertility }\end{array}$ & Total & $\mathrm{X}^{2}$ & p-value \\
\hline $0-<35$ & 277 & 537 & 814 & 13.6668 & 0.0002182748 \\
$35-<70$ & 66 & 231 & 297 & & \\
Total & 343 & 768 & 1111 & & \\
\hline
\end{tabular}

Table 2. Relationships between occupation and diagnosis.

\begin{tabular}{cccccc}
\hline & \multicolumn{2}{c}{ Diagnosis } & & & \\
Occupation & $\begin{array}{c}\text { Primary } \\
\text { infertility }\end{array}$ & $\begin{array}{c}\text { Secondary } \\
\text { infertility }\end{array}$ & Total & $\mathrm{X}^{2}$ & p-value \\
\cline { 2 - 4 } Business & 57 & 192 & 249 & 43.0519 & 0.0000 \\
Farmer & 6 & 22 & 28 & \\
Hair dresser & 19 & 78 & 97 & \\
House wife & 63 & 102 & 165 & \\
Seamstress & 30 & 67 & 97 & \\
Student & 55 & 48 & 103 & \\
Jobs with salary & 113 & 259 & 372 & \\
Total & 343 & 768 & 1111 & \\
\hline
\end{tabular}

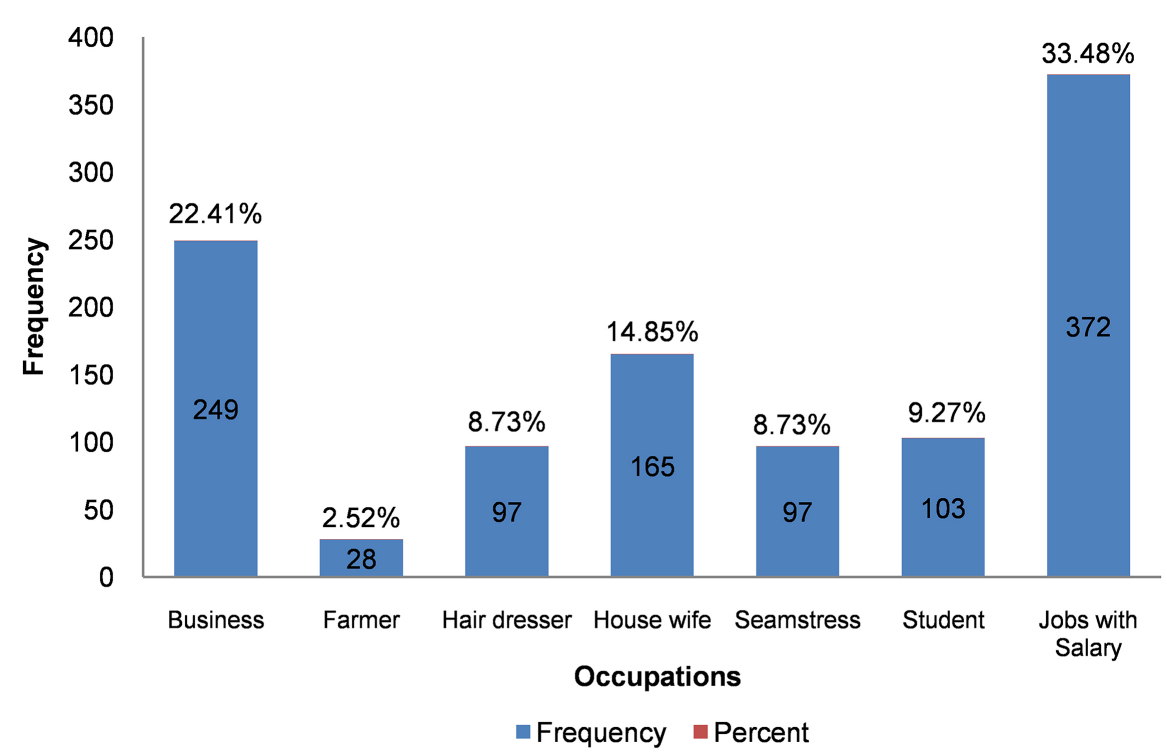

Figure 3. Distribution of infertility by occupation. 
Figure 4 indicates the distribution of laboratory analysis carried out in the two hospitals. Here, sexually transmitted infections (STIs) were the most diagnosed causes for infertility in the Southwest region attesting that infertility in this region of Cameroon is mostly attributed to sexually transmitted infections.

This study showed correlation between the three variables: occupation, diagnosis and age group as indicated in Table 3 and Table 4 . It highlights that primary and secondary infertility was greatest in women with jobs with salary for women less than 35 years old and in women above 35 years.

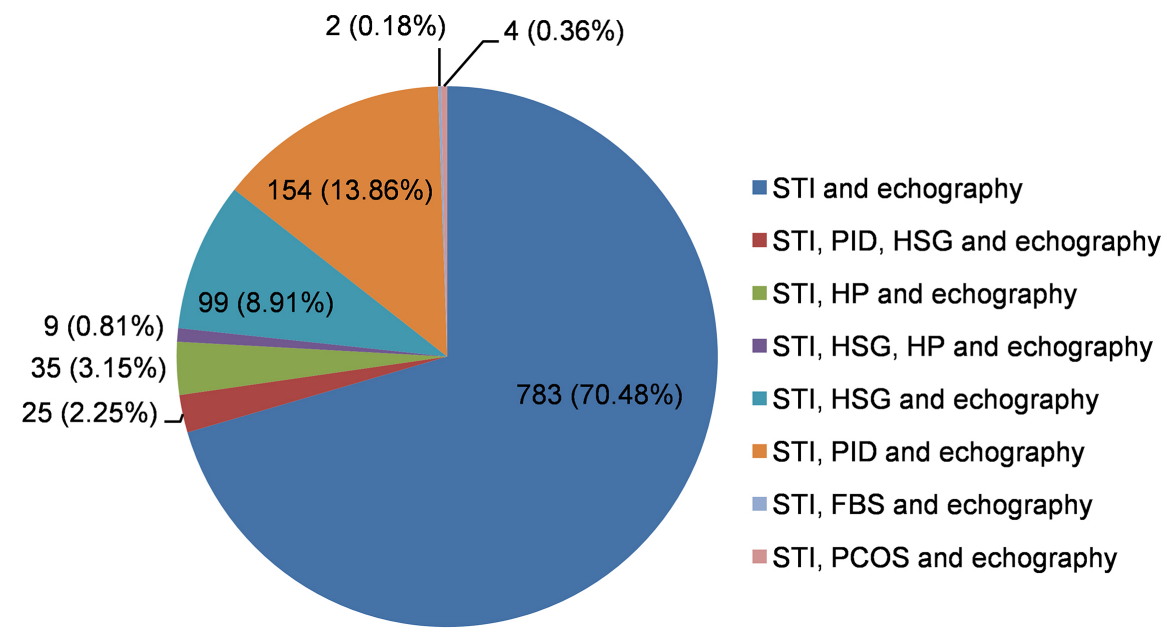

Figure 4. Distribution of infertility according to laboratory investigation performed. STI: Sexually transmitted infections; PID: Pelvic inflammatory disease; HSG: Hyterosalpingogram; HP: Hormone profile FBS: Fasting blood sugar; PCOS: Polycystic ovarian syndrome.

Table 3. Relationships between occupation, diagnosis and age group (less than 35 years).

\begin{tabular}{|c|c|c|c|c|c|}
\hline \multirow[b]{2}{*}{ Occupation } & \multicolumn{2}{|c|}{ Diagnosis } & \multirow[b]{2}{*}{ Total } & \multirow[b]{2}{*}{$\mathrm{X}^{2}$} & \multirow[b]{2}{*}{ p-value } \\
\hline & $\begin{array}{c}\text { Primary } \\
\text { infertility }\end{array}$ & $\begin{array}{l}\text { Secondary } \\
\text { infertility }\end{array}$ & & & \\
\hline Business & 35 & 118 & 153 & 40.6621 & 0.0000 \\
\hline Farmer & 5 & 15 & 20 & & \\
\hline Hair dresser & 16 & 64 & 80 & & \\
\hline House wife & 57 & 76 & 133 & & \\
\hline Seamstress & 29 & 54 & 83 & & \\
\hline Student & 55 & 45 & 100 & & \\
\hline Jobs with salary & 80 & 165 & 245 & & \\
\hline Total & 277 & 537 & 814 & & \\
\hline
\end{tabular}


Table 4. Association between occupation, diagnosis and age group (greater than 35 years).

\begin{tabular}{|c|c|c|c|c|c|}
\hline \multirow[b]{2}{*}{ Occupation } & \multicolumn{2}{|c|}{ Diagnosis } & \multirow[b]{2}{*}{ Total } & \multirow[b]{2}{*}{$\mathrm{X}^{2}$} & \multirow[b]{2}{*}{ p-value } \\
\hline & $\begin{array}{l}\text { Primary } \\
\text { infertility }\end{array}$ & $\begin{array}{l}\text { Secondary } \\
\text { infertility }\end{array}$ & & & \\
\hline Business & 22 & 74 & 96 & 4.6323 & 0.5918 \\
\hline Farmer & 1 & 7 & 8 & & \\
\hline Hair dresser & 3 & 14 & 17 & & \\
\hline House wife & 6 & 26 & 32 & & \\
\hline Seamstress & 1 & 13 & 14 & & \\
\hline Student & 0 & 3 & 3 & & \\
\hline Jobs with salary & 33 & 94 & 127 & & \\
\hline Total & 66 & 231 & 297 & & \\
\hline
\end{tabular}

\section{Discussion}

The prevalence of infertility in this study was $24.1 \%$ from 2015 to 2019 , which indicates that infertility is a major reproductive health problem in the Southwest region which merits special attention. It is higher than that previously reported in South East Asia and Sub-Saharan Africa with a global statistic of 10\% - 15\% [3]. The prevalence of primary infertility was $7.44 \%$ consistent with other authors who reported $6.6 \%-26.4 \%$ and $5 \%-25.7 \%$ in developed and less developed countries respectively [14]. The prevalence of secondary infertility was $16.6 \%$ which is lower than that reported by Larser (2000) that Cameroon and Central African Republic rank among the countries with the highest prevalence of secondary infertility reaching, respectively, $20 \%$ and $25 \%$ of women age 20 44. We had similar findings with other authors from Nigeria and Kenya estimating secondary infertility in the middle range from $10 \%$ to $18 \%$ for women age 20 - 44 [10] [23].

We realized that secondary infertility has the highest rate of $69 \%$ as opposed to primary infertility (31\%) which is consistent with the results of other studies conducted in sub-Sahara Africa [3] [9] [19]. This is accounted for mainly by sexually transmitted infections partly due to poor personal and environmental hygiene in the study area. In contrast to our study, only $23 \%$ of infertile couples in Asia and 16\% in North Africa suffered from secondary infertility [10] [19] [24]. This discrepancy may be due to different study design, sample size and culture.

The average age of primary and secondary infertility in this study was 29.61 and 31.86 respectively. We had a statistically significant value of $p<0.0002$ as 
shown in Table 4 indicating that age is a predisposing factor of female infertility corroborating other findings. Though there is a natural decline in ovarian function with age, Figure 2(b) shows that infertility increases up to 35 years and declines above that age. This shows that most cases of infertility are detected when birth rate is high i.e. below 35 when most women desire to have children in Cameroon and fewer cases are reported after 35 when birth rate is decreasing. This is further supported by the higher number of women in the non-salary jobs who are likely to have children below 35 years than the smaller number of women with salary job likely to have children above 35 due to career development. Therefore infertility is more likely to occur and be reported below 35 years.

Salary jobs had the highest cases of about 372 of the distribution of occupational status of women with infertility in the Southwest region of Cameroon (Table 1). This finding can be due to the fact that most salary jobs need educational training thereby prolonging the age of conceiving to a later date which affects the ovarian reserves that decrease with increasing age [21] [24]. Women's level of education is one of the factors affecting female infertility. Adamson et al reported that postponed marriage and delay in pregnancy can increase the risk of infertility in educated women. Business women and women working as artisans (seamstresses, hairdresser and farmer) representing 249 (22.4\%) and 167 (15.0\%) respectively are often associated with a lot of stress and stress-related factors leading to the release of more stress hormones and increase of the risk of infertility [8] [10].

Reproductive tract infections are important in the causation of infertility and the indicator used in our findings in laboratory investigation is sexually transmitted infections (STIs) and echography with about 783 (70.48\%). This result is in line with other reports indicating that STIs as the leading causes of infertility in Africa [23] [24]. A large study conducted by the WHO in 25 countries, with over 5800 couples, indicated that over $85 \%$ of the infertility among African women was attributable to infection, compared to $33 \%$ in women worldwide [20]. Genital infections represent one of the most important causes of infertility, affecting fallopian tubes, endometrial mucosa and the pelvis. Chlamydia and gonorrhea are most common STIs which lead to infertility in men and women if left untreated [8].

\section{Conclusion}

This study has shown that infertility in the Southwest region of Cameroon is high with a prevalence of $24 \%$, secondary infertility was also prominently diagnosed with a prevalence of $17.6 \%$. The high infertility was very significantly associated with age and occupation. The majority of the affected couples suffered from the preventable sexually transmitted infections (STIs). Hence there is a need for routine laboratory screening of women of reproductive age alongside sensitization on preventive measures. 


\section{Study Limitations}

A retrospective study was conducted with data collected from patients' files. Therefore, there was a challenge of missing or incomplete data giving a non representative population. However, the findings capture the general trend on infertility in the Southwest region of Cameroon which could influence further studies. Also it was a hospital-based survey and thus may not give an accurate estimate of the prevalence of infertility in the general population since only those couples seeking care would be counted.

\section{Conflicts of Interest}

The authors declare no conflicts of interest regarding the publication of this paper.

\section{References}

[1] Cong, J., Li, P., Zheng, L. and Tan, J. (2016) Prevalence and Risk Factors of Infertility at a Rural Site of Northern China. PLOS ONE, 11, e0155563. https://doi.org/10.1371/journal.pone.0155563

[2] Rodriguez-Purata, J. and Polyzos, N.P. (2018) The Endometrium during and after Ovarian Hyperstimulation and the Role of Segmentation of Infertility Treatment. Best Practice \& Research Clinical Endocrinology \& Metabolism, 33, 61-75. https://doi.org/10.1016/j.beem.2018.09.003

[3] Azam, M.I.D., Roozbeh, N., Yaghoobi, H., Soltani, S., Dashti, S., Shahrahmani, N. and Banaei, M. (2019) Etiology and Risk Factors Associated with Infertility. International Journal of Women's Health and Reproduction Sciences, 7, 346-353. https://doi.org/10.15296/ijwhr.2019.57

[4] Kawwass, J.F., Crawford, S., Kissin, D.M., Session, D.R., Boulet, S. and Jamieson, D.J. (2013) Tubal Factor Infertility and Perinatal Risk after Assisted Reproductive Technology. Obstetrics \& Gynecology, 121, 1263-1271. https://doi.org/10.1097/AOG.0b013e31829006d9

[5] Zegers-Hochschild, F., Adamson, G.D., de Mouzon, J., Ishihara, O., Mansour, R., Nygren, K., et al. (2009) International Committee for Monitoring Assisted Reproductive Technology (ICMART) and the World Health Organization (WHO) Revised Glossary of ART Terminology. Fertility and Sterility, 92, 1520-1524. https://doi.org/10.1016/j.fertnstert.2009.09.009

[6] World Health Organization (2006) Reproductive Health and Research. Reproductive Health Indicators: Guidelines for Their Generation, Interpretation and Analysis for Global Monitoring. World Health Organization, Geneva. https://www.who.int/reproductivehealth/publications/monitoring/924156315x/en

[7] Elhussein, O.G., Ahmed, M.A., Suliman, S.O., Yahya, L.I. and Adam, I. (2019) Epidemiology of Infertility and Characteristics of Infertile Couples Requesting Assisted Reproduction in a Low-Resource Setting in Africa, Sudan. Fertility Research and Practice, 5, Article No. 7. https://doi.org/10.1186/s40738-019-0060-1

[8] Direkvand-Moghadam, A., Delpisheh, A. and Khosravi, A. (2013) Epidemiology of Female Infertility; a Review of Literature. Biosciences, Biotechnology Research Asia, 10, 559-567. https://doi.org/10.13005/bbra/1165

[9] Tabong, P.T.-N. and Adongo, B.B. (2013) Understanding the Social Meaning of In- 
fertility and Childbearing: A Qualitative Study of the Perception of Childbearing and Childlessness in Northern Ghana. PLOS ONE, 8, e54429.

https://doi.org/10.1371/journal.pone.0054429

[10] Mascarenhas, M.N., Flaxman, S.R., Boerma, T., Vanderpoel, S. and Stevens, G.A. (2012) National, Regional, and Global Trends in Infertility Prevalence since 1990: A Systematic Analysis of 277 Health Surveys. PLOS Medicine, 9, e1001356. https://doi.org/10.1371/journal.pmed.1001356

[11] Akinsola, E.F. (2013) Cultural Variations in Parenting Styles in the Majority World Evidences from Nigeria and Cameroon. In: Seidl-de-Moura, M.L., Ed., Parenting in South American and African Contexts, IntechOpen, London, 81-83. https://doi.org/10.5772/57003

[12] Eric, S.N., Cyriac, D.D., Justine, B., Jean, L. and Noël, P.J. (2017) Who Is Responsible for Couple Infertility: A Clinic-Based Survey in Ouagadougou (Burkina Faso). International Journal of Nursing and Midwifery, 9, 10-16. https://doi.org/10.5897/IJNM2016.0238

[13] Adamson, P.C., Krupp, K., Freeman, A.H., Klausner, J.D., Reingold, A.L. and Madhivanan, P. (2011) Prevalence \& Correlates of Primary Infertility among Young Women in Mysore, India. Indian Journal of Medical Research, 134, 440-446.

[14] Kaadaaga, H.F., Ajeani, J., Ononge, S., et al. (2014) Prevalence and Factors Associated with Use of Herbal Medicine among Women Attending an Infertility Clinic in Uganda. BMC Complementary and Alternative Medicine, 14, 27. https://doi.org/10.1186/1472-6882-14-27

[15] Boivin, J., Bunting, L., Collins, J.A. and Nygren, K.G. (2007) International Estimates of Infertility Prevalence and Treatment-Seeking: Potential Need and Demand for Infertility Medical Care. Human Reproduction, 22, 1506-1512. https://doi.org/10.1093/humrep/dem046

[16] Olooto, W.E., Amballi, A.A. and Banjo, T.A. (2012) A Review of Female Infertility: Important Etiological Factors and Management. Journal of Microbiology and Biotechnology Research, 2, 379-385.

[17] Deyhoul, N., Mohamaddoost, T. and Hosseini, M. (2017) Infertility-Related Risk Factors: A Systematic Review. International Journal of Women's Health and Reproduction Sciences, 5, 24-29. http://www.ijwhr.net https://doi.org/10.15296/ijwhr.2017.05

[18] Abarikwu, S.O. (2013) Causes and Risk Factors for Male-Factor Infertility in Nigeria. African Journal of Reproductive Health, 17, 150.

[19] Larsen, U. (2000) Primary and Secondary Infertility in Sub-Saharan African. International Journal of Epidemiology, 29, 285-291. https://doi.org/10.1093/ije/29.2.285

[20] Ulla, L. (2003) Infertility in Central Africa. International Journal of Tropical Medicine and International Health, 8, 354-367. https://doi.org/10.1046/j.1365-3156.2003.01039.x

[21] Gwet-Bell, E., Gwet, B.B., Akoung, N. and Fiadjoe, M.K. (2018) The 5 Main Challenges Faced in Infertility Care in Cameroon. Global Reproductive Health, 3, e16.

[22] Leke, R.J.I. (1993) Regional and Geographic Variations in Infertility: Effects of Environmental, Cultural, and Socioeconomic Factors. Environmental Health Perspectives Supplements, 101, 73-80. https://doi.org/10.1289/ehp.93101s273

[23] Beninguisse, G. and De Brouwere, V. (2004) Tradition and Modernity in Cameroon: The Confrontation between Social Demand and Biomedical Logics of Health Services. African Journal of Reproductive Health, 8, 152-175. 
https://doi.org/10.2307/3583401

[24] Zegers-Hochschild, F., Adamson, G.D., Dyer, S., Racowsky, C., de Mouzon, J., Sokol, R., Rienzi, L., Sunde, A., Schmidt, L., Cooke, I.D., Simpson, J.L. and van der Poell, S. (2017) The International Glossary on Infertility and Fertility Care 2017. Fertility and Sterility, 108, 393-406. https://doi.org/10.1016/j.fertnstert.2017.06.005 
Research Questionnaire for a Rectospective Study of the Prevalence of Female Infertility in the Southwest Region of Cameroon

\section{A. Demographic Profile of Clients File}

Date of review: Time:

1) Clients ID 2) Name of Community

3) Name of Interviewee

4) Age of Respondent:

$$
\begin{aligned}
& 1=\text { Under 20 } \\
& 4=41-50
\end{aligned}
$$

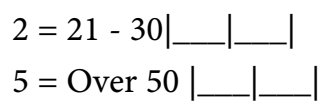

$$
\begin{aligned}
& 3=31-40 \\
& 6=\text { Don't know }
\end{aligned}
$$

5) Age of respondents husband/partner:

$$
\begin{aligned}
& 1=\text { Under 20|___ } \\
& 2=21-30 \\
& 5=\text { Over } 50 \\
& 3=31-40 \\
& 4=41-50
\end{aligned}
$$

_________

6) Level of education completed by Respondent: None/Informal School:

$$
1 \text { Primary } 2 \text { Secondary } 3 \text { Tertiary } 4 \text { Other : (specify) }
$$

7) Level of education completed by Respondent's husband/partner: None/Informal School,

1 Primary 2 Secondary 3 Tertiary 4 Other: $($ specify $)=$

8) Marital status:
1. Married
2. Never married before
3. Cohabitation
4. Widowed
5. Separated
6. Other

9) Major occupation of respondent:
1. Jobs with salary
2. Farming
3. Business
4. Student
5. Artisan (Seamstress, hair dresser, etc)
6. House wife

\section{B. Reproductive Behaviour and Characteristics}

1) Duration of respondent's current marriage:

2) Age of menarch

3) Diagnosis: 1. Primary infertility 2. Secondary infertility

4) Complaint.

5) Laboratory investigations:

1 sexually transmitted infection (STI) and echography,

2. STI, PID, HSG and echography,

3. STI, echography and Hormone profile,

4. STI, HSG, echography and hormone profile

5. STI, HSG and echography,

6. STI, PID and echography,

7. STI PCOS and echography

8. STI, FBS and echography.

NOTE: STI: Sexually transmitted infections; PID: Pelvic inflammatory disease; HSG: Hyterosalpingogram; HP: Hormone profile FBS: Fasting blood sugar; PCOS: Polycystic ovarian syndrome

THANK YOU FOR YOUR COOPERATION 